\title{
Hormonal responses following eccentric exercise in humans*
}

\author{
Anastassios Philippou, ${ }^{1}$ Maria Maridaki, ${ }^{2}$ Roxane Tenta, ${ }^{3}$ Michael Koutsilieris ${ }^{1}$ \\ ${ }^{1}$ Department of Experimental Physiology, Medical School, National and Kapodistrian University of Athens, Greece; \\ ${ }^{2}$ Department of Sports Medicine \& Biology of Physical Activity, School of Physical Education and Sport Science, National \\ and Kapodistrian University of Athens, Greece; ${ }^{3}$ Department of Nutrition \& Dietetics, School of Health Science and \\ Education, Harokopio University
}

\begin{abstract}
OBJECTIVE: Mechanically overloaded muscle and its subsequent damage are strong stimuli for eliciting acute hormonal changes, while the muscle adaptation which occurs following exercise-induced muscle damage may involve complex hormonal responses before the completion of muscle regeneration. The purpose of this study was to investigate systemic responses of various hormones, as well as secreted proteins that are exercise-regulated and associated with muscle adaptation, for several days after eccentric exercise-induced muscle damage in humans. DESIGN: Nine young male volunteers performed 50 maximal eccentric muscle actions using the knee extensor muscles of both legs. Blood samples were drawn before and at 6 , 48 and 120 hours post exercise and serum levels of growth hormone (GH), insulin-like growth factor binding protein-3 (IGFBP-3), cortisol, prolactin, thyroid-stimulating hormone (TSH), free thyroxine (fT4), irisin, follistatin and sclerostin were measured. Myoglobin (Mb) concentration and lactate dehydrogenase (LDH) activity were also evaluated as indirect markers of muscle damage. RESULTS: Significant alterations in Mb and LDH were observed over time after eccentric exercise $(p=0.039-0.001)$. A late serum increase in fT4 and decrease in irisin levels, along with an early and persistent decrease in IGFBP-3 levels, were observed following the muscle-damaging exercise $(p=0.049-0.016)$. GH, cortisol, prolactin, TSH, follistatin and sclerostin exhibited moderate changes during the recovery period after exercise, though without reaching statistical significance $(p>0.05)$, while correlational analyses revealed significant associations between GH and IGFBP-3, prolactin and sclerostin over time $(p=0.049-0.001)$. CONCLUSIONS: The significant hormonal responses observed in this study may indicate their involvement in the regenerative mechanisms following muscle damage, potentially as part of a regulatory network to support a normal adaptation process after muscle-damaging exercise.
\end{abstract}

Key words: Follistatin, IGFBP-3, Irisin, Muscle damage, Prolactin, Sclerostin, TSH, T4

\section{Address for correspondence:}

Dr. Michael Koutsilieris, MD, Ph.D, Department of Experimental Physiology, Medical School, National and Kapodistrian University of Athens, 75 Micras Asias Str., 11527 Athens, Greece; Tel: +30 210 7462506, Fax: +30 210 7462571, E-mail: mkoutsil@med.uoa.gr Received: 04-07-2017, Accepted: 10-01-2018

* This work was presented at the 1st Conference of the Institute of Stress Biology and Medicine (ISBM) entitled: "Systems Biology-Medicine and Stress", held in Athens on 20-22 January 2017 


\section{INTRODUCTION}

Skeletal muscle overloading and overstretch, or their combination, that occur in eccentric muscle actions have been extensively shown to result in muscle damage, thus eccentric exercise has been utilized as a well characterized model to study contraction-induced muscle damage and its consequent responses. ${ }^{1-3}$ Eccentric exercise-induced muscle damage has been associated with structural and functional disturbances in the exercised muscle, with changes in its mechanical properties, loss of muscle fiber integrity and leakage of muscle proteins into the blood being some well characterized responses to muscle damage. ${ }^{4-7}$

Mechanical overloading of muscle and its subsequent damage appear to be strong stimuli for eliciting significant acute hormonal responses, which may be more critical to muscle tissue repair, remodelling and growth than chronic exercise-induced changes in hormonal levels at rest. ${ }^{8,9}$ Moreover, hormones are sensitive to exercise-induced stress and play various roles in the anabolic/catabolic and metabolic drive in muscle. Thus, muscle regeneration and adaptation which occur following exercise-induced muscle damage are likely to involve complex systemic responses of hormones and muscle-associated secreted proteins before the completion of muscle regeneration. Such potential interactions between hormones and other secreted proteins could therefore be part of an integrated system of signalling to mediate and support physiological adaptations to muscle mechanical overloading and damage, ${ }^{9}$ hence, the net result of eccentric exercise-induced hormonal, metabolic and anabolic responses appears to be a novel adaptive signal within the muscle. ${ }^{10}$

However, although much has been learned about the local mechanisms and the cellular and molecular interactions that mediate muscle regeneration and adaptation following exercise-induced muscle damage, ${ }^{11-14}$ the role of systemic, and particularly hormonal, responses to muscle damage and its subsequent adaptations is still not fully defined. Only a limited number of studies have examined the acute exercise-induced hormonal responses following mechanical overloading (resistance exercise) or muscledamaging eccentric exercise in humans, ${ }^{9,15-17}$ while in those studies only few hormones, such as cortisol, testosterone or growth hormone $(\mathrm{GH})$, have been investigated and this only for a short period of time, i.e. less than one hour, after exercise.

Thus, the challenge remains to further characterize the simultaneous systemic responses of various hormones and muscle-associated proteins during the regeneration process after muscle-damaging exercise in the context of their potential interactions in the regulation of muscle damage-induced adaptation. The purpose of this study was therefore to examine the eccentric exercise-induced responses of hormones ${ }^{8}$ as well as secreted proteins that are exercise-regulated and have been associated with skeletal muscle regeneration and adaptation, ${ }^{18-20}$ i.e. GH, insulin-like growth factor binding protein-3 (IGFBP-3), cortisol, prolactin, thyroid-stimulating hormone (TSH), free thyroxine (fT4), irisin, follistatin and sclerostin. Indeed, some of these hormones have aroused particular interest because of their potential role in exercise-induced muscle adaptations. ${ }^{19-24}$ In particular, irisin is a hormone predominantly expressed in human muscle ${ }^{25,26}$ and is required for the exercise-induced conversion of white adipose tissue to brown. ${ }^{18,25}$ In addition, follistatin is an antagonist of myostatin, the negative regulator of muscle regeneration, ${ }^{27}$ while sclerostin is a mechanical loading-regulated protein whose serum levels have been shown to be affected by physical exercise..$^{20,28}$

We monitored the serum changes of the aforementioned hormones and muscle-associated secreted proteins for several days after the completion of an eccentric exercise protocol in humans, posing the hypothesis that their circulating levels would be changed during the recovery period following exercise-induced muscle damage, thus suggesting their potential role as mediators of muscle regeneration and adaptation after the damaging exercise.

\section{MATERIALS AND METHODS}

\section{Ethical approval}

All volunteers provided written informed consent to participate in this study, which was approved by the Ethics Committee of the National and Kapodistrian University of Athens, while all experimental procedures conformed to the Declaration of Helsinki. 


\section{Subjects}

Nine healthy men (age $25.7 \pm 1.7$ years, height 180.4 $\pm 1.7 \mathrm{~cm}$, body mass $77.2 \pm 2.7 \mathrm{~kg}$, body mass index $23.7 \pm 0.6$ ) participated in the study. The participants were physically active but had not participated in any type of resistance training or regular exercise regime for at least 6 months before the study and also were unaccustomed to high-intensity eccentric exercise. These volunteers were free of any lower extremity musculoskeletal disorders; they also refrained from taking any nutritional supplementations or medications throughout the experimental period. In addition, the subjects were not allowed to perform any vigorous physical activities during the entire experimental period. They were also instructed to maintain their habitual diet and on the day prior to and the day of each blood draw to have equivalent meals.

\section{Experimental design}

The participants performed a maximal eccentric exercise protocol of the knee extensors with each leg. Before and at 6, 48 and $120 \mathrm{hrs}$ after the eccentric exercise, blood samples were collected from each individual volunteer. The blood sampling time-points were chosen to cover an adequate period within the regenerative phase following exercise-induced damage. ${ }^{29}$

\section{Eccentric exercise protocol}

The subjects performed an eccentric exercise bout with the knee extensors of each leg on an isokinetic dynamometer (Cybex Norm Lumex, Inc., Ronkonkoma, NY, USA), which has been shown to result in muscle damage. ${ }^{3}$ Briefly, before the exercise protocol the subjects completed a familiarization session in which they were acquainted with the procedure of the eccentric exercise with each leg. The exercise protocol consisted of 2 sets of 25 maximal voluntary eccentric (lengthening) muscle actions in isokinetic mode, while a 5-min break was allowed between the sets.

\section{Blood sampling and serum analyses}

Blood samples were withdrawn prior to and after the exercise bout (at 6, 48 and $120 \mathrm{hrs}$ post exercise) and at the same time of the day for all subjects. The participants were seated quietly for $30 \mathrm{~min}$ and 10 $\mathrm{ml}$ of blood were drawn. Blood samples allowed to clot at room temperature for $30 \mathrm{~min}$ and serum was collected after centrifugation at 4,000 RPM for 10 min at $4{ }^{\circ} \mathrm{C}$, stored frozen in $0.5 \mathrm{ml}$ aliquots at $-80^{\circ} \mathrm{C}$ and only thawed once for analysis. Serum myoglobin $(\mathrm{Mb})$ concentration and lactate dehydrogenase $(\mathrm{LDH})$ activity were assessed as indirect markers of muscle damage. In particular, measurement of LDH activity was performed using an automated commercially available kit (Roche Diagnostics, Mannheim, Germany) in a Roche/Hitachi ACN 057 (Roche, Mannheim, Germany) at $37^{\circ} \mathrm{C}$, while myoglobin concentrations were determined using an immunoturbidimetric assay (Turbiquant, Dade Behring, Marburg, Germany).

Serum GH, insulin-like growth factor binding protein-3 (IGFBP-3), cortisol, prolactin, thyroidstimulating hormone (TSH), free thyroxine (fT4), irisin, follistatin and sclerostin were determined by standard sandwich enzyme-linked immunosorbent assay (ELISA) protocols using commercially available kits (GH and cortisol: Enzo Life Sciences, NY, USA; IGFBP-3, follistatin and sclerostin: Quantikine HS, R\&D Systems inc., MN, USA; prolactin: Cayman Chemical, Michigan, USA; TSH and fT4: MP Biomedicals, NY, USA; irisin: Adipogen, Switzerland) according to the manufacturer's instructions. The colour formation was measured by a microplate reader (Versamax, Molecular Devices, CA, USA) at $450 \mathrm{~nm}$ and calculations were carried out using SoftMax Pro software (Molecular Devices, CA, USA). All samples were run simultaneously, analyzed in duplicate and the results were averaged. According to the manufacturers, the minimal detection limits of the assays used were $0.93 \mathrm{pg} \mathrm{ml}^{-1}, 56.72 \mathrm{pg} \mathrm{ml}^{-1}$, $0.05 \mathrm{ng} \mathrm{ml}^{-1}, 0.12 \mathrm{ng} / \mathrm{ml}, 0.05 \mu \mathrm{IU} \mathrm{ml}^{-1}, 0.054 \mathrm{ng}$ $\mathrm{dl}^{-1}, 1 \mathrm{ng} \mathrm{ml}^{-1}, 83 \mathrm{pg} \mathrm{ml}^{-1}, 3.8 \mathrm{pg} \mathrm{ml}^{-1}$ for $\mathrm{GH}$, cortisol, IGFBP-3, prolactin, TSH, fT4, irisin, follistatin and sclerostin, respectively, while the intra- and inter-assay coefficient of variation $(\mathrm{CV})$ were as follows: $4.0 \%$ to $4.2 \%$ and $1.9 \%$ to $6.4 \%$ for $\mathrm{GH}$, $7.3 \%$ to $10.5 \%$ and $7.8 \%$ to $13.4 \%$ for cortisol, 2.3 $\%$ to $5.0 \%$ and $5.4 \%$ to $8.0 \%$ for IGFBP-3, $2.8 \%$ to $4.1 \%$ and $4.6 \%$ to $5.5 \%$ for prolactin, $6.4 \%$ to $9.2 \%$ and $7.6 \%$ to $12.9 \%$ for TSH, $3.3 \%$ to $10.9 \%$ and $6.0 \%$ to $10.8 \%$ for fT $4,4.9 \%$ to $8.2 \%$ and $8.1 \%$ to $9.7 \%$ for irisin, $2.0 \%$ to $2.7 \%$ and $7.1 \%$ to $9.2 \%$ for follistatin and $1.8 \%$ to $2.1 \%$ and $8.2 \%$ to $10.8 \%$ for sclerostin. 


\section{Statistical analysis}

One-way analysis of variance (ANOVA) with repeated measures over time was used to evaluate changes in all serum measurements (SPSS v. 22 statistical package). A non-parametric (Friedman) test was conducted where the data had violated the assumptions necessary to run the repeated measures one-way ANOVA (e.g., data not normally distributed). Where a significant $F$ ratio was found for main effect $(p<0.05)$, the means were compared using Dunnett's post-hoc test or Wilcoxon signed-rank test with Bonferroni correction for non-parametric tests. Pearson's correlation coefficient ( $r$ ) was used to determine correlations between variables. All data are presented as mean \pm standard error of the mean (S.E.M). The level of significance was set at $\mathrm{p}<0.05$.

\section{RESULTS}

Significant alterations in markers of muscle damage were observed after eccentric exercise. Specifically, LDH activity levels were increased significantly $(\mathrm{F}=3.99, \mathrm{df}=3)$ at $6(\mathrm{p}=0.003)$ and 48 $\mathrm{hrs}(\mathrm{p}=0.019)$ following muscle-damaging exercise and remained elevated up to $120 \mathrm{hrs}$ post exercise. Myoglobin concentrations were significantly increased $(\mathrm{F}=12.94, \mathrm{df}=3)$ at $6(\mathrm{p}<0.001)$ and $120 \mathrm{hrs}$ $(\mathrm{p}=0.039)$ post exercise, while both $\mathrm{LDH}$ and $\mathrm{Mb}$ showed their peak response at $6 \mathrm{hrs}$ post exercise (Figure 1).

Standard curves of the ELISA analyses (absorbance vs concentration) of all the factors examined had an $\mathrm{R}^{2}$ coefficient ranging between 0.971 and 1. Systemic responses of the various hormones and muscle-associated secreted proteins after the muscledamaging exercise are shown in Table 1. GH, cortisol and prolactin showed moderate increases following eccentric exercise, which peaked at $6 \mathrm{hrs}$ for $\mathrm{GH}$ and cortisol and at $48 \mathrm{hrs}$ for prolactin, however without reaching statistical significance due to a large variability shown between the subjects' responses ( $>>0.05$; Table 1). TSH increased gradually but not significantly up to $120 \mathrm{hrs}$ post-exercise $(\mathrm{p}>0.05)$, while fT4 also exhibited gradual increases post exercise, which became significant $(\mathrm{F}=2.77, \mathrm{df}=3)$ at 48 $(\mathrm{p}=0.016)$ and $120 \mathrm{hrs}(\mathrm{p}=0.049)$ following eccentric exercise (Table 1).
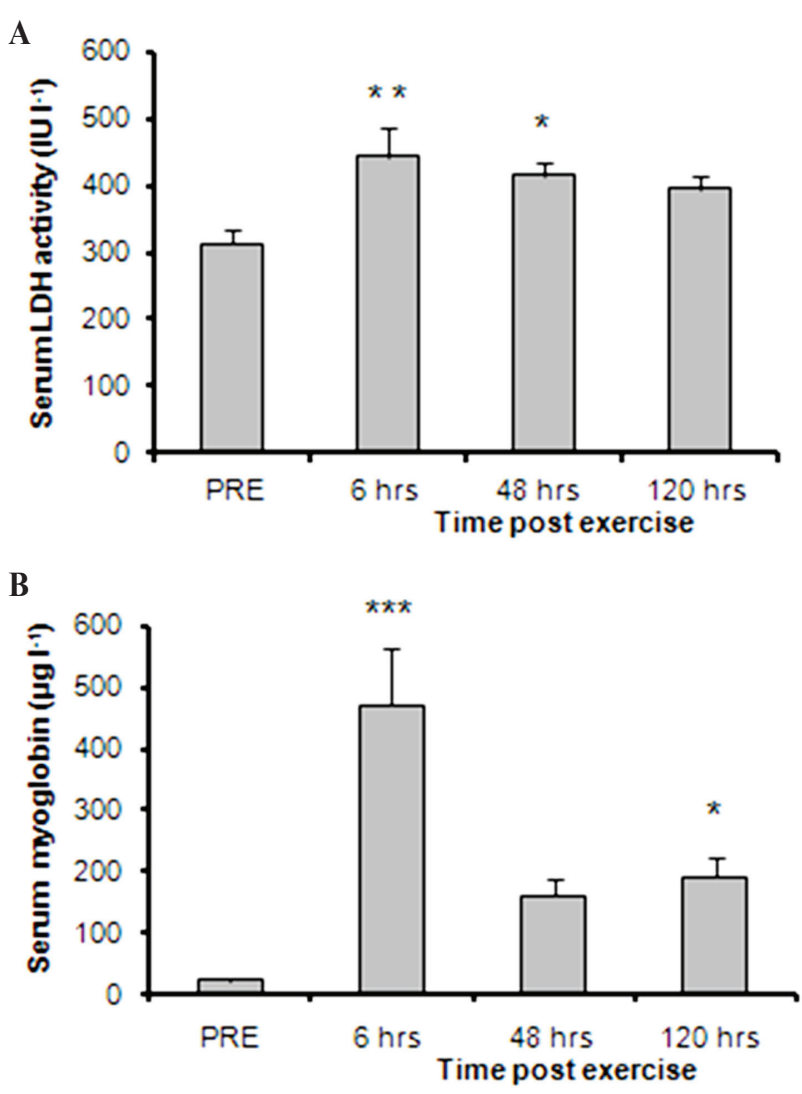

Figure 1. Changes in serum (A) lactate dehydrogenase (LDH) activity and $(\mathrm{B})$ myoglobin $(\mathrm{Mb})$ concentration over time compared with the pre-exercise (PRE) levels (mean \pm S.E.M.; $n=9$ ). Significantly different from pre-exercise; $*$ : $<0.05, * *: p<0.01$, $* * *: p<0.001$.

Interestingly, serum levels of both IGFBP-3 and irisin decreased post exercise and they were significantly lower $(\mathrm{F}=2.14, \mathrm{df}=3)$ for irisin at $120 \mathrm{hrs}$ post exercise compared with the baseline (PRE) levels $(p=0.032$; Table 1). Furthermore, when the postexercise responses were analyzed as percent changes in relation to baseline levels significant changes were revealed over time for IGFBP-3, irisin and fT4 (Figure 2). In particular, IGFBP-3 decreased significantly throughout the post-exercise period $(p<0.011-0.001)$, irisin showed a significant decrease $120 \mathrm{hrs}(\mathrm{p}=0.003)$ after exercise, while fT4 exhibited a gradual increase following eccentric exercise, reaching statistical significance at $48(\mathrm{p}=0.004)$ and $120 \mathrm{hrs}(\mathrm{p}=0.009)$ post exercise (Figure 2).

Serum levels of follistatin peaked at $48 \mathrm{hrs}$, showing a more than $60 \%$ increase before returning to baseline levels at $120 \mathrm{hrs}$ post exercise, while sclerostin 
Table 1. Serum concentrations of various hormones and muscle-associated secreted proteins examined at baseline and 6, 48 and 120 hrs after muscle damaging eccentric exercise. Values represent the means $( \pm$ S.E.M $),(n=9)$

\begin{tabular}{lcccc}
\hline & PRE & $\mathbf{6}$ hrs & $\mathbf{4 8 ~ h r s}$ & 120 hrs \\
\hline GH $(\mathrm{pg} / \mathrm{ml})$ & $495.6( \pm 152.8)$ & $726.1( \pm 169.1)$ & $665.1( \pm 217.1)$ & $510.4( \pm 152.8)$ \\
IGFBP-3 $(\mathrm{ng} / \mathrm{ml})$ & $1391.9( \pm 8.0)$ & $1216.2( \pm 7.0)$ & $1236.2( \pm 7.1)$ & $1247.7( \pm 8.0)$ \\
Cortisol $(\mathrm{ng} / \mathrm{ml})$ & $267.0( \pm 40.8)$ & $337.4( \pm 77.3)$ & $321.4( \pm 60.0)$ & $312.1( \pm 43.0)$ \\
Prolactin $(\mathrm{ng} / \mathrm{ml})$ & $23.4( \pm 3.1)$ & $28.1( \pm 4.7)$ & $30.2( \pm 4.1)$ & $25.7( \pm 4.6)$ \\
TSH $(\mu \mathrm{IU} / \mathrm{ml})$ & $1.09( \pm 0.14)$ & $1.27( \pm 0.15)$ & $1.17( \pm 0.20)$ & $1.33( \pm 0.17)$ \\
fT4 $(\mathrm{ng} / \mathrm{dl})$ & $1.13( \pm 0.02)$ & $1.20( \pm 0.05)$ & $1.29( \pm 0.04)^{*}$ & $1.26( \pm 0.05)^{*}$ \\
& & & $(\mathrm{p}=0.016)$ & $(\mathrm{p}=0.049)$ \\
Irisin $(\mu \mathrm{g} / \mathrm{ml})$ & $0.22( \pm 0.03)$ & $0.20( \pm 0.02)$ & $0.17( \pm 0.01)$ & $0.14( \pm 0.02)^{*}$ \\
& & & & $(\mathrm{p}=0.032)$ \\
Follistatin $(\mathrm{pg} / \mathrm{ml})$ & $2080.2( \pm 200.3)$ & $2827.2( \pm 472.6)$ & $2924.4( \pm 330.2)$ & $2144.4( \pm 177.9)$ \\
Sclerostin $(\mathrm{pg} / \mathrm{ml})$ & $1734.0( \pm 639.1)$ & $1432.8( \pm 491.5)$ & $1280.5( \pm 533.4)$ & $2239.1( \pm 1066.1)$ \\
\hline
\end{tabular}

GH: Growth hormone; IGFBP-3: Insulin-like growth factor binding protein-3; TSH: Thyroid-stimulating hormone; fT4: Free thyroxine. *: Significantly different compared with the pre-exercise (PRE) values.
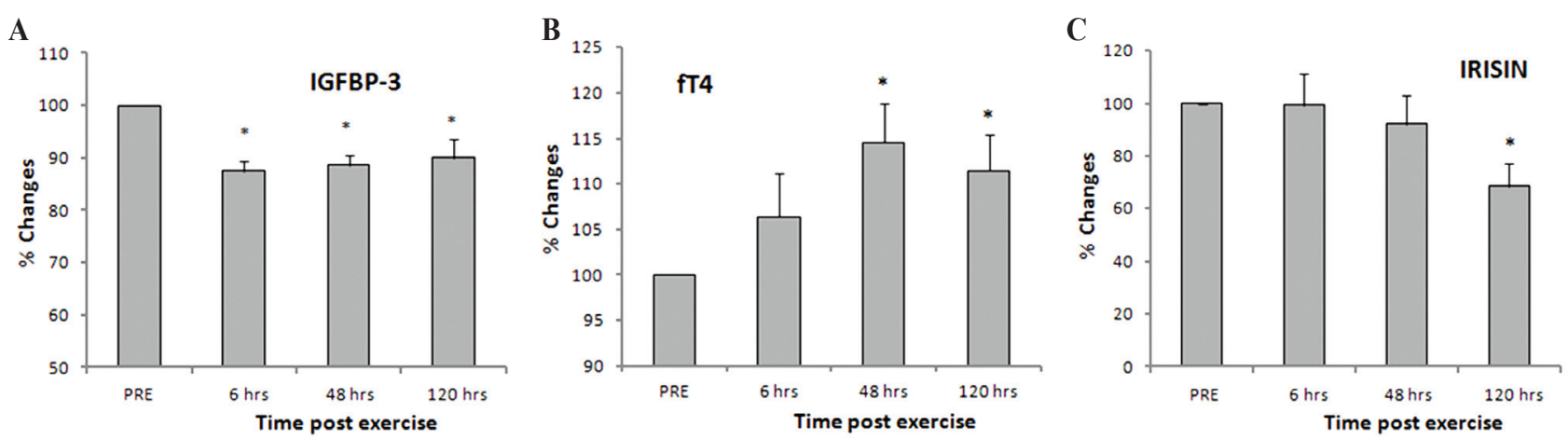

Figure 2. Percent changes of serum (A) insulin-like growth factor binding protein-3 (IGFBP-3), (B) free thyroxine (fT4), and (C) irisin over time in relation to their pre-exercise (PRE) levels (mean \pm S.E.M.; $n=9$ ). Significantly different from pre-exercise; *: $p<0.05$.

exhibited a reverse pattern of response over time, decreasing gradually before exhibiting a late mild increase at $120 \mathrm{hrs}$ post eccentric exercise, though those changes failed to reach significance due to a large individual variation in the circulating levels of these secreted factors $(\mathrm{p}>0.05$; Table 1$)$.

Correlation analyses revealed significant positive associations over time between $\mathrm{GH}$ and prolactin $(\mathrm{r}=0.585-0.671 ; \mathrm{p}=0.037-0.010)$, as well as between $\mathrm{GH}$ and sclerostin $(\mathrm{r}=0.560-0.852 ; \mathrm{p}=0.046-0.001)$. Moreover, a significant negative correlation was found between GH and IGFBP-3 serum levels over time $[r=-0.420-(-0.537) ; p=0.049]$.

\section{DISCUSSION}

Our study examined the changes in the circulating levels of various hormones and secreted proteins associated with skeletal muscle regeneration and adaptation up to 5 days after an eccentric exercise protocol in order to reveal their potential involvement and interactions in the regeneration process following exercise-induced muscle damage. The remarkable and sustained changes in the indirect markers of damage, i.e. the leakage of muscle proteins $\mathrm{Mb}$ and $\mathrm{LDH}$ into circulation post exercise, indicated that the eccentric exercise used in this study did result in muscle damage. Our main findings demonstrated 
a late serum increase in fT4 and decrease in irisin levels, along with an early and persistent decrease in IGFBP-3 levels after exercise. To the best of the authors' knowledge, this is the first study to show significant systemic responses of $\mathrm{T} 4$ and irisin during the regeneration period following muscle-damaging exercise, indicating the involvement of those hormones in the regenerative and adaptive mechanisms following muscle damage. Furthermore, the present study revealed moderate systemic increases in TSH, $\mathrm{GH}$, cortisol and prolactin over time, while circulating levels of secreted proteins follistatin and sclerostin also exhibited modest alterations post exercise.

An exercise bout represents physical stress for the body and induces an acute disturbance of its homeostasis, particularly in the exercised muscles but also in other cells and organs, while in the recovery phase homeostasis is re-established. ${ }^{30,31}$ Specifically, regulatory mechanisms appear to be quickly reengaged after a mechanical overloading (resistance) exercise workout so that homeostasis is restored within 1 hour post exercise. ${ }^{8}$ However, following muscledamaging exercise, a longer, highly orchestrated sequence of responses is activated, initially associated with an inflammatory and degenerative phase at the site of damage and followed by the myogenic differentiation and fusion of myoblasts to complete muscle regeneration. ${ }^{29}$

Although the role of thyroid hormones during muscle regeneration is not as yet fully defined, it is well known that skeletal muscle is a major target of thyroid hormone signalling while, further, this signalling regulates crucial biological functions, including energy expenditure, development and growth. In particular, expression of the thyroid hormone converting enzyme type 2 iodothyronine deiodinase (DIO2), which converts the prohormone $\mathrm{T} 4$ to the active hormone $\mathrm{T} 3$, is increased in developing or injured muscle and provides the potential for local control of the uptake of T4 as well as of its activation and inactivation within skeletal muscle. ${ }^{24}$ Moreover, there is compelling evidence of a functional link between DIO2 induction and myogenic differentiation ${ }^{24}$ and also of an essential role of thyroid hormone signalling in muscle regeneration after injury. ${ }^{23,32}$ Hence, the late elevated circulating levels of fT4, and to a lesser extent of TSH, found in the present study during the recovery period after muscle damage appear to corroborate the aforementioned functional interactions between thyroid hormones and muscle regeneration and further suggest the potential contribution of the circulating thyroid hormones, especially of thyroxine, to muscle regeneration following damaging exercise. Nevertheless, the importance of fT4 increase post exercise needs further investigation, since the main effect of thyroid hormones on myocyte growth and metabolism is exerted by the active hormone T3. Moreover, the increased circulating fT4 levels could be a result of a decreased systemic (from the liver and/or kidney) activity of DIO2, which might result in normal serum levels of T3. In addition, the increased, though not significantly, cortisol levels found in this study could also lead to the inhibition of peripheral conversion of $\mathrm{T} 4$ to $\mathrm{T} 3$.

On the other hand, thyroid hormones are influencing factors in controlling energy balance and their signalling can modulate metabolic rate by either decreasing metabolic efficiency or by uncoupling ATP synthesis in the mitochondria of skeletal muscle. Indeed, increased mitochondrial uncoupling in muscle and raised energy expenditure have been exhibited by individuals who had been treated with a T4 synthetic analogue and also by patients who had elevated serum thyroid hormone levels. ${ }^{33,34}$ Moreover, recent studies may have, ${ }^{29}$ or may have not revealed ${ }^{30}$ an association between thyroid hormones and the musclederived circulating protein, irisin, in thyrometabolic abnormalities. Irisin, apart from being required for the exercise-induced conversion of white adipose tissue to brown, ${ }^{18,25}$ promotes mitochondrial uncoupling in brown adipose tissue, thereby pointing to an important indirect role of muscle in the regulation of energy expenditure. ${ }^{24}$ Thus, it could be postulated that the gradually decreased circulating levels of irisin observed in the present study could influence adipose tissue metabolism and insulin resistance ${ }^{35}$ during the recovery period following muscle-damaging exercise. At this point it should be mentioned that there are claims that many human irisin antibodies used in commercial ELISA kits lack required specificity and that when this hormone was measured by the precise mass spectrometry method ${ }^{36}$ considerably lower concentrations of circulating irisin were detected (i.e., 
$\sim 3.6-4.3 \mathrm{ng} / \mathrm{ml}$ ) compared to the results of our study and others. It is thus worth noting this limitation of our study, although it was clearly stated that irisin unequivocally circulates and is regulated by exercise in humans. ${ }^{36}$ Taking into account all the above, we might speculate that the significantly decreased levels of irisin concurrently with the increased circulating fT4 levels may reflect a compensatory mechanism to counterbalance the raised energy expenditure expected to be induced by the elevated levels of T4 during regeneration of the damaged muscles. ${ }^{33,34}$

The final outcome of the multiple events that take place following muscle damage is also influenced by a crucial balance between, among others, anabolic and catabolic factors. Nevertheless, less is known about the systemic responses of competitive (anabolic vs catabolic) hormones, such as GH and cortisol, during regeneration after muscle damage. Previous studies examining the more acute hormonal responses to mechanical overloading or muscle-damaging exercise have shown significant increases of those hormones during the next hour post exercise. ${ }^{15-17}$ Such early responses may reflect the metabolic and/or physiological stress of exercise, whereas the late hormonal changes in the circulation are reflective of tissue homeostasis mechanisms involving protein metabolism and tissue repair during the recovery process. ${ }^{8,37}$

The findings of our study suggest that eccentric exercise triggers only moderate adaptive changes of the anabolic/catabolic and physiological stressregulated hormones, ${ }^{30}$ while the positive relationship found between $\mathrm{GH}$ and prolactin over time imply a systemic counterregulation of the anabolic and catabolic processes during the adaptation following muscle-damaging exercise.

Further, in this context, this study was the first focusing on the systemic responses of follistatin after exercise-induced muscle damage. Follistatin has been shown to promote myogenic differentiation in vitro, as well as hypertrophy and muscle regeneration after injury in vivo, through myostatin blockage but also via myostatin-driven independent mechanisms. ${ }^{19,21,38} \mathrm{We}$ revealed a pattern of response of follistatin similar to that of GH. Although these increases in the levels of follistatin were not significantly high, they might imply the potential involvement of circulating follistatin as well in the regenerative and or anabolic adaptations following exercise-induced muscle damage, which is in accordance with recent findings regarding the therapeutic effects of systemic follistatin administration on muscle regeneration..$^{22}$

Another interesting finding of our study was the decreased serum IGFBP-3 levels throughout the 5-day recovery period after exercise, which were negatively correlated with the corresponding GH levels. In general, IGFBPs and particularly IGFBP-3 can modulate the IGF-dependent effects, both in the circulation and in the extracellular environment, via regulation of IGF-1 concentration and its local bioavailability in the tissue ${ }^{39}$ We previously did not find any significant changes in serum IGF-1 levels throughout a period of 16 days following muscle-damaging exercise. ${ }^{12}$ However, less is known concerning late IGFBP-3 systemic responses after exercise-induced muscle damage. Another study showed that circulating levels of IGFBP-3 were only increased for the first hour after a mechanical overloading exercise and further suggested that the acute effect of a resistance exercise bout is not the changes in circulating IGF-1 levels but rather the manner in which this anabolic factor is partitioned among its binding proteins. ${ }^{40}$ Moreover, a potentiation of IGF activity by IGFBP-3 has been demonstrated in many in vitro systems, leading to the concept that cell association and processing of IGFBP-3 to a form of reduced affinity to IGF-1 is involved in the enhancement of the availability of IGF-1 to its receptor(s), ${ }^{41,42}$ while, further, GH induces IGFBP-3 local accumulation in cells. ${ }^{43}$ Hence, we could speculate that GH and IGFBP-3 responses and their negative correlations found in this study may indicate a GH-induced tissue accumulation of circulating IGFBP-3 as a mechanism of potentiating the regenerative and anabolic effects of IGF-1 following muscle damage. ${ }^{12,44,45}$

Lastly, we explored the potential responses of sclerostin, which is secreted by osteocytes and acts as an inhibitor of bone formation and whose serum levels appear to be affected by physical exercise..$^{20,28}$ In particular, 8 wk of exercise training resulted in significantly decreased serum levels of sclerostin; however, there are no reports in the literature regarding the acute effects of muscle mechanical overloading and damage 
on circulating levels of this secreted factor. Interestingly, in this study we observed a gradual decrease of circulating sclerostin up to $48 \mathrm{hrs}$ after the single bout of eccentric exercise, before increasing (though without reaching significance) at $120 \mathrm{hrs}$ post exercise, accompanied by its strong positive correlations with GH responses. More studies are needed to identify the potential interactions between muscle-damaging exercise and acute systemic responses of sclerostin.

In conclusion, the significant systemic hormonal responses observed in this study may point to their involvement in the regenerative mechanisms following muscle damage. It can be assumed that hormones and secreted factors released into the circulation act as part of a regulatory network to support a normal adaptation process following muscle-damaging exercise. Further studies are required to characterize the mechanisms by which hormonal responses are triggered and regulated at the systemic level during recovery after exercise-induced muscle damage. Moreover, it would be of particular interest to investigate the end organ effects of the above hormonal alterations on target organs other than the damaged skeletal muscle, thus revealing potential clinical implications of this particular type of exercise.

\section{ACKNOWLEDGEMENTS}

The authors are grateful to the study participants for their invaluable contribution to this research.

\section{CONFLICTS OF INTEREST}

The authors declare no conflict of interest.

\section{REFERENCES}

1. Proske U, Morgan DL, 2001 Muscle damage from eccentric exercise: mechanism, mechanical signs, adaptation and clinical applications. J Physiol 537: 333-345.

2. Philippou A, Bogdanis GC, Nevill AM, Maridaki M. Changes in the angle-force curve of human elbow flexors following eccentric and isometric exercise. Eur J Appl Physiol 2004; 93: 237-244.

3. Philippou A, Maridaki M, Bogdanis G, et al, 2009 Changes in the mechanical properties of human quadriceps muscle after eccentric exercise. In Vivo 23: 859-865.

4. Philippou A, Koutsilieris M, Maridaki M, 2012 Changes in kinematic variables at various muscle lengths of human elbow flexors following eccentric exercise. J Muscle Res Cell Motil 33: 167-175.

5. Philippou A, Maridaki M, Bogdanis GC, 2003 Anglespecific impairment of elbow flexors strength after isometric exercise at long muscle length. J Sports Sci 21: 859-865.

6. Peake J, Nosaka K, Suzuki K, 2005 Characterization of inflammatory responses to eccentric exercise in humans. Exerc Immunol Rev 11: 64-85.

7. Kanda K, Sugama K, Hayashida H, et al, 2013 Eccentric exercise-induced delayed-onset muscle soreness and changes in markers of muscle damage and inflammation. Exerc Immunol Rev 19: 72-85.

8. Kraemer WJ, Ratamess NA, 2005 Hormonal responses and adaptations to resistance exercise and training. Sports Med 35: 339-361.

9. Izquierdo M, Ibanez J, Calbet JA, et al, 2009 Cytokine and hormone responses to resistance training. Eur J Appl Physiol 107: 397-409.

10. Douglas J, Pearson S, Ross A, McGuigan M, 2017 Eccentric Exercise: Physiological Characteristics and Acute Responses. Sports Med 47: 663-675.

11. Karalaki M, Fili S, Philippou A, Koutsilieris M, 2009 Muscle regeneration: cellular and molecular events. In Vivo 23: 779-796.

12. Philippou A, Papageorgiou E, Bogdanis G, et al, 2009 Expression of IGF-1 isoforms after exercise-induced muscle damage in humans: characterization of the MGF E peptide actions in vitro. In Vivo 23: 567-575.

13. Peake JM, Neubauer O, Della Gatta PA, Nosaka K, (1985) 2017 Muscle damage and inflammation during recovery from exercise. J Appl Physiol 122: 559-570.

14. Bamman MM, Shipp JR, Jiang J, et al, 2001 Mechanical load increases muscle IGF-I and androgen receptor mRNA concentrations in humans. Am J Physiol Endocrinol Metab 280: E383-390.

15. Smilios I, Tsoukos P, Zafeiridis A, et al, 2014 Hormonal responses after resistance exercise performed with maximum and submaximum movement velocities. Appl Physiol Nutr Metab 39: 351-357.

16. Kraemer RR, Hollander DB, Reeves GV, et al, 2006 Similar hormonal responses to concentric and eccentric muscle actions using relative loading. Eur J Appl Physiol 96: 551-557.

17. Durand RJ, Castracane VD, Hollander DB, et al, 2003 Hormonal responses from concentric and eccentric muscle contractions. Med Sci Sports Exerc 35: 937943.

18. Novelle MG, Contreras C, Romero-Pico A, et al, 2013 Irisin, two years later. Int J Endocrinol 2013: 46281.

19. Zhu J, Li Y, Lu A, et al, 2011 Follistatin improves skeletal muscle healing after injury and disease through an interaction with muscle regeneration, angiogenesis, and fibrosis. Am J Pathol 179: 915-930. 
20. Zagrodna A, Jozkow P, Medras M, et al, 2016 Sclerostin as a novel marker of bone turnover in athletes. Biol Sport 33: 83-7.

21. Winbanks CE, Weeks KL, Thomson RE, et al, 2012 Follistatin-mediated skeletal muscle hypertrophy is regulated by Smad3 and mTOR independently of myostatin. J Cell Biol 197: 997-1008.

22. Yaden BC, Croy JE, Wang Y, et al, 2014 Follistatin: a novel therapeutic for the improvement of muscle regeneration. J Pharmacol Exp Ther 349: 355-371.

23. Dentice M, Marsili A, Ambrosio R, et al, 2010 The FoxO3/type 2 deiodinase pathway is required for normal mouse myogenesis and muscle regeneration. J Clin Invest 120: 4021-4030.

24. Salvatore D, Simonides WS, Dentice M, et al, 2014 Thyroid hormones and skeletal muscle--new insights and potential implications. Nat Rev Endocrinol 10: 206-214.

25. Bostrom P, Wu J, Jedrychowski MP, et al, 2012 A PGC1-alpha-dependent myokine that drives brownfat-like development of white fat and thermogenesis. Nature 481: 463-468.

26. Huh JY, Panagiotou G, Mougios V, et al, 2012 FNDC5 and irisin in humans: I. Predictors of circulating concentrations in serum and plasma and II. mRNA expression and circulating concentrations in response to weight loss and exercise. Metabolism 61: 1725-1738.

27. Lee SJ, McPherron AC, 2001 Regulation of myostatin activity and muscle growth. Proc Natl Acad Sci U S A 98: 9306-9311.

28. Ardawi MS, Rouzi AA, Qari MH, 2012 Physical activity in relation to serum sclerostin, insulin-like growth factor-1, and bone turnover markers in healthy premenopausal women: a cross-sectional and a longitudinal study. J Clin Endocrinol Metab 97: 3691-3699.

29. Philippou A, Maridaki M, Theos A, Koutsilieris M, 2012 Cytokines in muscle damage. Adv Clin Chem 58: 49-87.

30. Mastorakos G, Pavlatou M, Diamanti-Kandarakis E, Chrousos GP, 2005 Exercise and the stress system. Hormones (Athens) 4: 73-89.

31. de Graaf-Roelfsema E, Keizer HA, van Breda E, et al, 2007 Hormonal responses to acute exercise, training and overtraining. A review with emphasis on the horse. Vet Q 29: 82-101.

32. Marsili A, Tang D, Harney JW, et al, 2011 Type II iodothyronine deiodinase provides intracellular 3,5,3'-triiodothyronine to normal and regenerating mouse skeletal muscle. Am J Physiol Endocrinol Metab 301: E818-E824.

33. Mitchell CS, Savage DB, Dufour S, et al, 2010 Re- sistance to thyroid hormone is associated with raised energy expenditure, muscle mitochondrial uncoupling, and hyperphagia. J Clin Invest 120: 1345-1354.

34. Johannsen DL, Galgani JE, Johannsen NM, et al, 2012 Effect of short-term thyroxine administration on energy metabolism and mitochondrial efficiency in humans. PLoS One 7: e40837.

35. Gouni-Berthold I, Berthold HK, Huh JY, et al, 2013 Effects of lipid-lowering drugs on irisin in human subjects in vivo and in human skeletal muscle cells ex vivo. PLoS One 8: e72858.

36. Jedrychowski MP, Wrann CD, Paulo JA, et al, 2015 Detection and Quantitation of Circulating Human Irisin by Tandem Mass Spectrometry. Cell Metab 22: 734740 .

37. Kraemer WJ, Ratamess NA, Nindl BC, (1985) 2017 Recovery responses of testosterone, growth hormone, and IGF-1 after resistance exercise. J Appl Physiol 122: 549-558.

38. Kalista S, Schakman O, Gilson H, et al, 2012 The type 1 insulin-like growth factor receptor (IGF-IR) pathway is mandatory for the follistatin-induced skeletal muscle hypertrophy. Endocrinology 153: 241-253.

39. Philippou A, Armakolas A, Koutsilieris M, 2013 Evidence for the possible biological significance of the IGF-1 gene alternative splicing in prostate cancer. Front Endocrinol (Lausanne) 4: 31.

40. Nindl BC, Kraemer WJ, Marx JO, et al, (1985) 2001 Overnight responses of the circulating IGF-I system after acute, heavy-resistance exercise. J Appl Physiol 90: 1319-1326.

41. Conover CA, 1991 Glycosylation of insulin-like growth factor binding protein-3 (IGFBP-3) is not required for potentiation of IGF-I action: evidence for processing of cell-bound IGFBP-3. Endocrinology 129: 3259-3268.

42. Baxter RC, 2000 Insulin-like growth factor (IGF)binding proteins: interactions with IGFs and intrinsic bioactivities. Am J Physiol Endocrinol Metab 278: E967-E976.

43. Ernst M, Rodan GA, 1990 Increased activity of insulinlike growth factor (IGF) in osteoblastic cells in the presence of growth hormone $(\mathrm{GH})$ : positive correlation with the presence of the GH-induced IGF-binding protein BP-3. Endocrinology 127: 807-814.

44. Philippou A, Maridaki M, Halapas A, Koutsilieris M, 2007 The role of the insulin-like growth factor 1 (IGF1) in skeletal muscle physiology. In Vivo 21: 45-54.

45. Philippou A, Halapas A, Maridaki M, Koutsilieris M, 2007 Type I insulin-like growth factor receptor signaling in skeletal muscle regeneration and hypertrophy. $\mathrm{J}$ Musculoskelet Neuronal Interact 7: 208-218. 